\title{
Aescin and diosmin each alone or in low dose- combination ameliorate liver damage induced by carbon tetrachloride in rats
}

\author{
Sara Mahmmoud EL-Dakhly ${ }^{1}$ Abeer Abdallah Ali Salama² ${ }^{0}$, Soha Osama Mahmoud Hassanin ${ }^{3}$, \\ Noha Nazeeh Yassen ${ }^{4}$, Alaaeldin Ahmed Hamza ${ }^{5}$ and Amr Amin ${ }^{6,7^{*}}$ (B)
}

\begin{abstract}
Objective: This study evaluated hepatoprotective effect of aescin (AES) and diosmin (DIO), individually or in lowdose combination in chemically induced liver injury in rats. Rats were divided into 6 groups; Group 1, control, Group 2 , injected with a single dose of a mixture of corn oil and carbon tetrachloride $\left(\mathrm{CCl}_{4}\right)$ to induce hepatic toxicity. Before $\mathrm{CCl}_{4}$ injection, Groups 3-6 were treated daily for 14 days with silymarin (SIL) (200 mg/kg), aescin (AES; 3.6 \& 1.75 mg/ $\mathrm{kg}$ ), Diosmin (DIO; 100 \& 50 mg/kg). Serum samples were analyzed for different liver function, oxidative stress and antioxidant markers. Moreover, inflammation and tissue damage were confirmed by histological staining of liver tissue sections.

Results: Results indicated that $\mathrm{CCl}_{4}$ elevated serum levels of all assessed liver function markers and decreased levels of key antioxidants. Administration of AES and/or DIO significantly reversed all those $\mathrm{CCl}_{4}$-induced effects. Histopathological study showed disruption of the hepatic architecture, necrosis and inflammatory cells and depositions of glycogen and protein in the tissues of $\mathrm{CCl}_{4}$-treated group. Pretreatment with $\mathrm{DIO}$ and/or AES significantly improved histopathological structure of liver tissue. In conclusion, low-dose combination of AES and DIO exhibited significant and preferential hepatoprotective activity compared to individual treatment with AES or DIO.
\end{abstract}

Keywords: Aescin, Diosmin, Carbon tetrachloride, Liver, Rats

\section{Introduction}

Liver damage is viewed as a worldwide medical and economic burden that is often inclined by viral infection, poisonous synthetic concoctions, and hepatotoxic drugs [1]. The liver assumes an irreplaceable job in the digestion of xenobiotics and therapeutic agents being detoxified and excreted [2]. Chemically-induced hepatic damage is mainly evoked by the metabolic change of chemical into free radicals, which can truly influence cell macromolecules [2]. Carbon tetrachloride $\left(\mathrm{CCl}_{4}\right)$-induced liver damage has been for quite some time utilized as hepatic

\footnotetext{
*Correspondence: a.amin@uaeu.ac.ae

${ }^{6}$ Biology Department, UAE University, AI Ain, UAE

Full list of author information is available at the end of the article
}

damage model to evaluate the therapeutic potential of drugs. This model has also been used in mechanical liver injuries that are comparable to human liver disease both in morphology and the biochemical characteristics of cellular lesions [2]. This hepatotoxic agent induces hepatic necrosis through the generation of trichloromethyl free radical under the effect of cytochrome p-450 2E1 [3].

Previous investigations have reported that a wide spectrum of natural products can prevent or even treat different types of liver diseases [4-9]. $\beta$-Aescin (AES) is a triterpene saponin derived from the horse chestnut tree Aesculus hippocastanum L. (Hippocastanaceae). Traditionally, leaves, bark and seeds were used to treat arthritis, brain trauma, stroke, venous congestion and thrombophlebitis [10]. There are different formulations

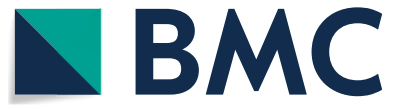

(c) The Author(s) 2020. This article is licensed under a Creative Commons Attribution 4.0 International License, which permits use, sharing, adaptation, distribution and reproduction in any medium or format, as long as you give appropriate credit to the original author(s) and the source, provide a link to the Creative Commons licence, and indicate if changes were made. The images or other third party material in this article are included in the article's Creative Commons licence, unless indicated otherwise in a credit line to the material. If material is not included in the article's Creative Commons licence and your intended use is not permitted by statutory regulation or exceeds the permitted use, you will need to obtain permission directly from the copyright holder. To view a copy of this licence, visit http://creativeco mmons.org/licenses/by/4.0/. The Creative Commons Public Domain Dedication waiver (http://creativecommons.org/publicdomain/ zero/1.0/) applies to the data made available in this article, unless otherwise stated in a credit line to the data. 
of AES in clinical applications, including oral tablets, injections, and topical gel. AES is widely used in the clinical therapy because of its anti-apoptotic, anti-edematous, anti-inflammatory, and antioxidant effects [11-13]. Moreover, some studies reported anti-inflammatory, anti-oxidative stress and protective effects of AES against liver damage induced in animals by endotoxin [14], methyl parathion [15] and $\mathrm{CCl}_{4}$ [16].

Diosmin (DIO) (3'5,7-trihydroxy-4'-methoxyflavone 7-rutinoside) is an unsaturated flavonoid glycoside, present in citrus fruits [17]. DIO formulations are used to treat chronic venous insufficiency, hemorrhoids, venous ulcers (especially of the lower limbs) and to prevent postoperative thromboembolism [18]. Previous investigations reported anti-inflammatory, anti-oxidative stress and protective effects of DIO against liver damage induced in animals by ethanol [19], methotrexate [20], iron [21] and by aflatoxin [22]. Moreover, DIO successfully relieved mitochondrial oxidative stress effect against isopropanolinduced myocardial injury in rats [23]. In that context, AES and DIO have received considerable attention to their tremendous potential for management of various forms of hepatopathy [14, 15, 19-22]. Assessing AES/ DIO and their combination against induced-liver damage is the objective of this study.

\section{Main text \\ Methods}

Chemicals

All chemicals were provided as detailed in (Additional file 1).

\section{Animals}

Male Wistar rats, weighing 100-130 g, were provided by the animal house colony of the National Research Centre, Dokki, Giza, Egypt. Animal-related procedures were all approved and operated in accordance with the Ethics Committee of the National Research Centre and followed the recommendations of the National Institutes of Health Guide for Care and Use of Laboratory Animals.

\section{Experimental design}

Rats were randomized and divided into six groups $(\mathrm{n}=6)$. Each was subjected to different treatment as detailed in (Additional file 1). Briefly, Control, received water $(5 \mathrm{ml} / \mathrm{kg}$ b.wt.) for 14 days then vehicle $(1 \mathrm{ml}$ corn oil $/ \mathrm{kg}$ b.wt.). $\mathrm{CCl}_{4}$ group received water $(5 \mathrm{ml} / \mathrm{kg} \mathrm{b.wt}$ ) then $\mathrm{CCl}_{4}\left(50 \% \mathrm{CCl}_{4} /\right.$ corn oil; $1 \mathrm{ml} / \mathrm{kg}$ body weight). Silymarin (SIL) $+\mathrm{CCL}_{4}$ group received SIL $(200 \mathrm{mg} / \mathrm{kg}$ b.wt.) [24] and $\mathrm{CCl}_{4}$ (50\% $\mathrm{CCl}_{4} /$ corn oil; $1 \mathrm{ml} / \mathrm{kg}$ b.wt. i.p.). The $\mathrm{AES}+\mathrm{CCl}_{4}$ group received AES $(3.6 \mathrm{mg} / \mathrm{kg}$ b.wt.) [16] and $\mathrm{CCl}_{4}\left(50 \% \mathrm{CCl}_{4} /\right.$ corn oil; $1 \mathrm{ml} / \mathrm{kg}$ b.wt. ip). $\mathrm{DIO}+\mathrm{CCl}_{4}$ group received DIO $(100 \mathrm{mg} / \mathrm{kg})$ [25] and $\mathrm{CCL}_{4}\left(50 \% \mathrm{CCl}_{4} /\right.$ corn oil; $1 \mathrm{ml} / \mathrm{kg}$ b.wt. ip). The $\mathrm{ASE}+\mathrm{DIO}+\mathrm{CCl}_{4}$ group received AES $(1.75 \mathrm{mg} / \mathrm{kg})$ and DIO $(50 \mathrm{mg} / \mathrm{kg})$ and then $\mathrm{CCL}_{4}\left(50 \% \mathrm{CCl}_{4} /\right.$ corn oil; $1 \mathrm{ml} /$ kg b.wt. ip).

\section{Sample collection and preparation}

Rats were anesthetized using diethyl ether then samples of blood were withdrawn from the retro-orbital plexus. Post blood collection, animals were euthanized by cervical dislocation under 3\% sodium pentobarbital anesthesia and livers were swiftly dissected out, washed with cold normal saline and weighted. Blood samples were centrifuged at $3000 \mathrm{rpm} \mathrm{g}$ for $10 \mathrm{~min}$ and serum was used for further biochemical analyses.

\section{Assessment of serum biochemical parameters}

Kits used were purchased from sources detailed in (Additional file 1).

\section{Histological and histochemical assessment studies}

After blood collection, rats of each group were euthanized by cervical dislocation under $3 \%$ sodium pentobarbital anesthesia, and their livers were collected, dissected immediately after the sacrifice and were used for the histopathological analysis as described in $[26,27]$ and detailed in (Additional file 1).

\section{Assessments of morphometric area percentage and optical density}

This assessment was carried out on periodic acid Schiff (PAS) \& Mercuric bromophenol blue stained slides. Assessed areas were analyzed as detailed in (Additional file 1).

\section{Statistical analyses}

Using statistical package for social science (SPSS), collected data were statistically analyzed as detailed in (Additional file 1).

\section{Results and discussion $A E S, D I O$ and their combination attenuated liver lesions in $\mathrm{CCl}_{4}$-induced liver damage}

Normal liver sections "control group" showed typical hepatic architecture with the central vein centrally located and normally thickened hepatic cords radiating with well-formed hepatocytes with centrally located nuclei and intact cell membrane (Fig. $1 \mathrm{~A}$ ). $\mathrm{CCl}_{4}$-induced group showed hepatocytes degenerative changes including pyknotic nuclei. In addition, central veins were massively enlarged and clogged with ductular cells hyperplasia, scattered inflammatory cells which were concentrated around hepatic vessels (Fig. 1B). Compared to the $\mathrm{SIL}+\mathrm{CCl}_{4}$ group (Fig. $3 \mathrm{C}$ ) and to the protected groups; 

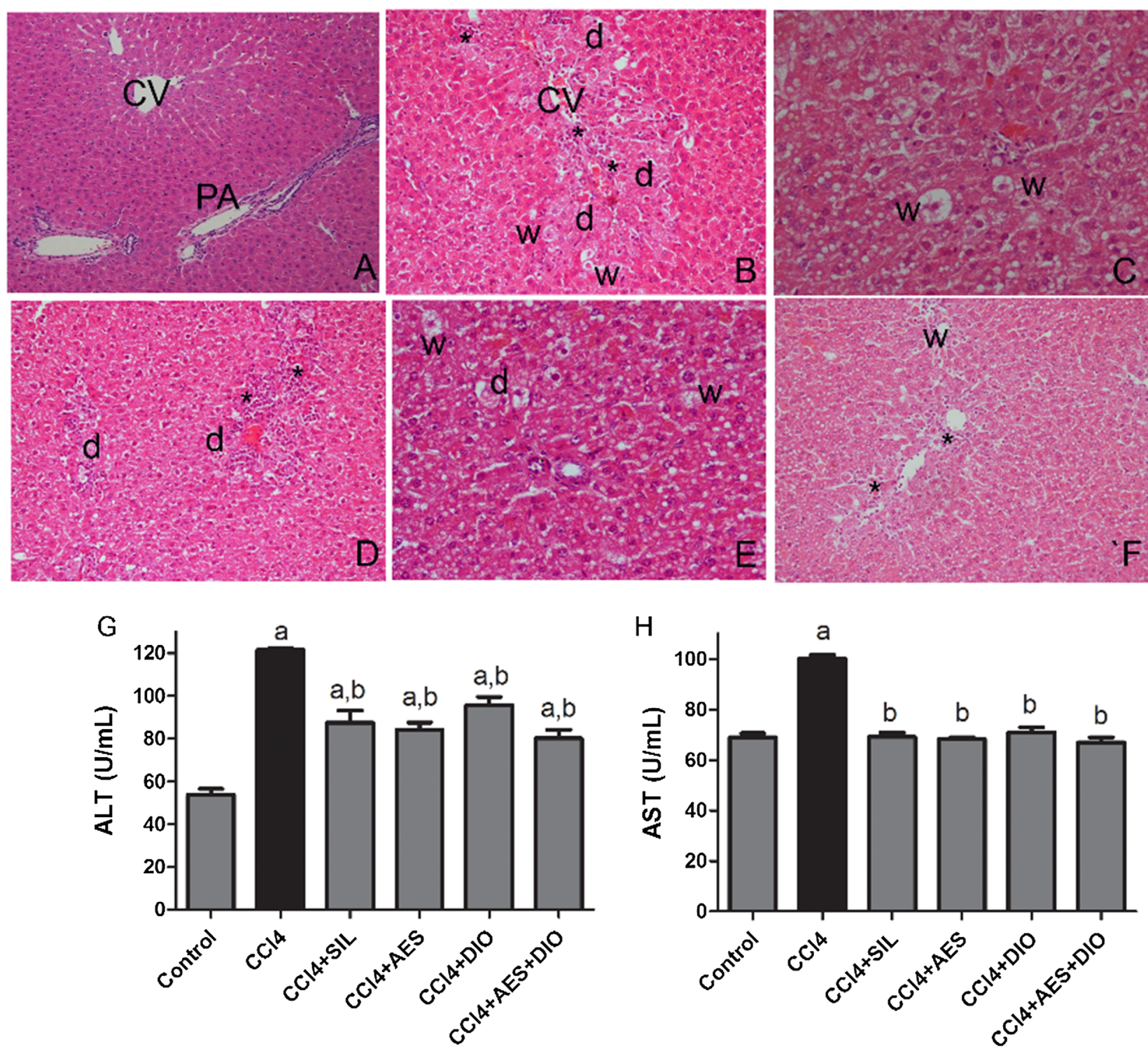

Fig. 1 Effects of AES and DIO each alone or in low-dose combination on $\mathrm{CCl}_{4}$-induced liver damage in rats. ( $\mathrm{n}=6$ per group). A-F Representative images of H\&E-stained hepatic sections of the different groups $(200 \times)$. C.V, (central vein), PA (portal area), Inflammatory cell infiltration (star), hepatic necrosis associated with degenerated nuclei (d) lipid droplets and vacuolization in hepatocytes (w). Serum markers of liver damage ALT (G), $\operatorname{AST}(\mathbf{H})$ activities. Data are presented as mean \pm SEM. $\left(n=6 /\right.$ group). a $P<0.05$ vs. control group. b $P<0.05$ vs. $C_{C L}$ group

treated with ASE (Fig. 3D), DIO (Fig. 1E), animals intoxicated with $\mathrm{CCl}_{4}$ and treated with both AES and DIO at low dose combination showed marked degree of improvement of hepatic tissue as the hepatic tissue restored its normal structure and architecture with centrally located central vein and intact hepatocytes (Fig. 1F). Currently, $\mathrm{CCl}_{4}$-induced liver injury is a model that is widely employed to screen for anti-hepatotoxic/hepatoprotective drugs. It is also a useful tool to study different liver illnesses, such as fatty liver, fibrosis, and cirrhosis [2, 28]. The magnitude of $\mathrm{CCl}_{4}$ hepatic impairment is evaluated by the enhanced serum level of cytoplasmic enzymes and by histopathologic changes in liver [29, 30].

Compared to control, $\mathrm{CCl}_{4}$-induced group had significantly higher levels of serum alanine aminotransferase (ALT) (130\%), and aspartate aminotransferase (AST) (40\%) (Fig. 1G, H). Levels of ALT and AST were significantly $(\mathrm{P} \leq 0.05)$ improved upon treatment with SIL, AES and DIO. Pretreatment with SIL, AES, DIO and their combination reduced the elevated serum ALT by $28 \%, 34 \%, 31 \%$ and $21 \%$, respectively, and AST levels by $31 \%, 33 \%, 29 \%$ and $32 \%$, respectively, 
compared to animals in $\mathrm{CCl}_{4}$ group (Fig. 1G, $\mathrm{H}$ ). Upregulation of ALT and AST have been ascribed to hepatotoxicity as they are released into blood serum upon hepatocyte degeneration [31]. The current study showed quite a restoration of almost normal levels especially when combined treatment was applied.

\section{Glycogen and proteins distribution}

Figure 2 shows the distribution of glycogen contents in normal liver tissue as reflected by PAS positivity area (Fig. 3A; $20.74 \pm 1.65$ ). $\mathrm{CCl}_{4}$ group showed severe depletion of glycogen $6.63 \pm 1.6$ with a reduction percent of $82.45 \%$ from the control group.

Groups treated with DIO, AES and both showed varying improvements in the glycogen content as reflected by the PAS area \% of $15.84 \pm 1.23,16.54 \pm 0.79$ and
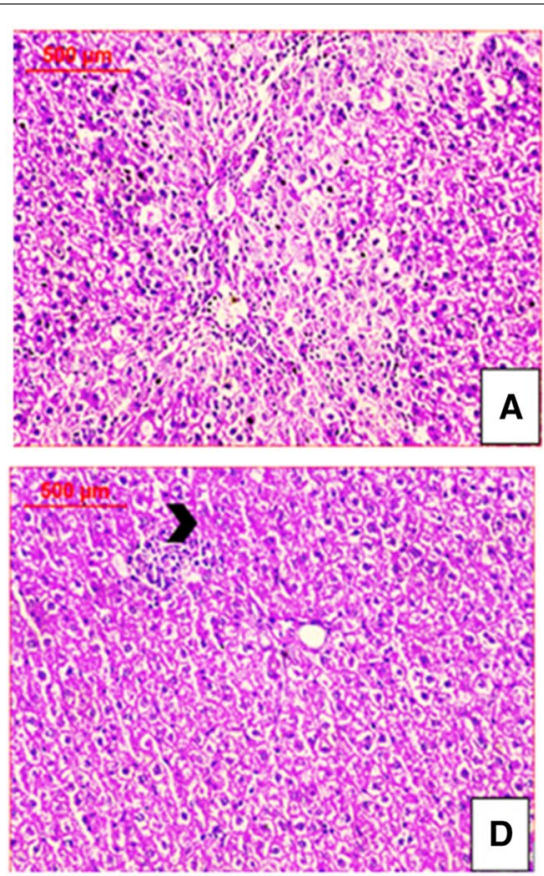
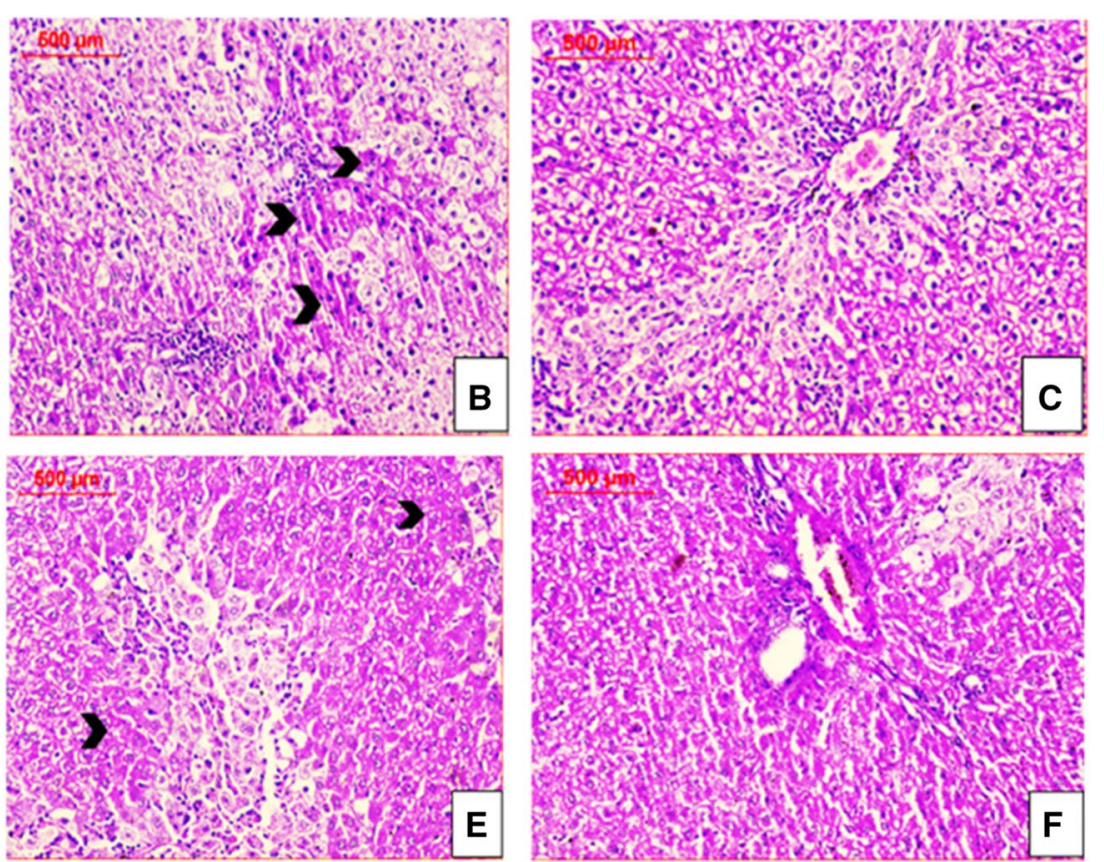

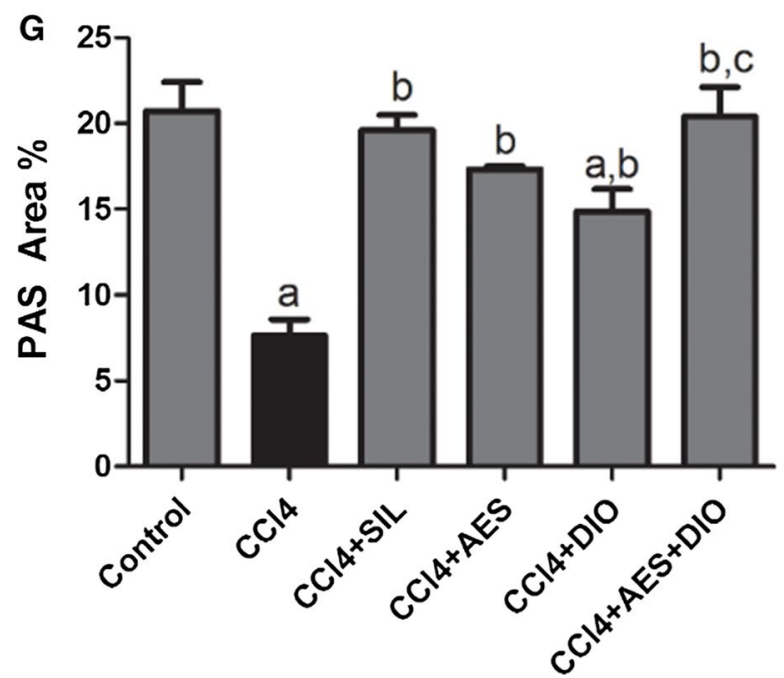

Fig. 2 Effects of AES and DIO each alone or in low-dose combination on the distribution of glycogen contents in liver tissue stained by PAS reagent in the $\mathrm{CCl}_{4}$-induced liver rat model. A-F Representative images of PAS staining (red area staining, arrow heads). $200 \times$ magnification, scale bar equals $500 \mu \mathrm{m}$. G PAS -positive area expression as a percentage of the total area across 10 different fields for each rat section using Leica Qwin 500 Image Analyzer. Data are presented as mean $\pm \mathrm{SEM}\left(\mathrm{n}=6\right.$ /group). a $\mathrm{P}<0.05$ vs. control group. b $\mathrm{P}<0.05$ vs. $C \mathrm{CL}_{4}$ group, $\mathrm{c} P<0.05$ vs $\mathrm{SIL}$ group 

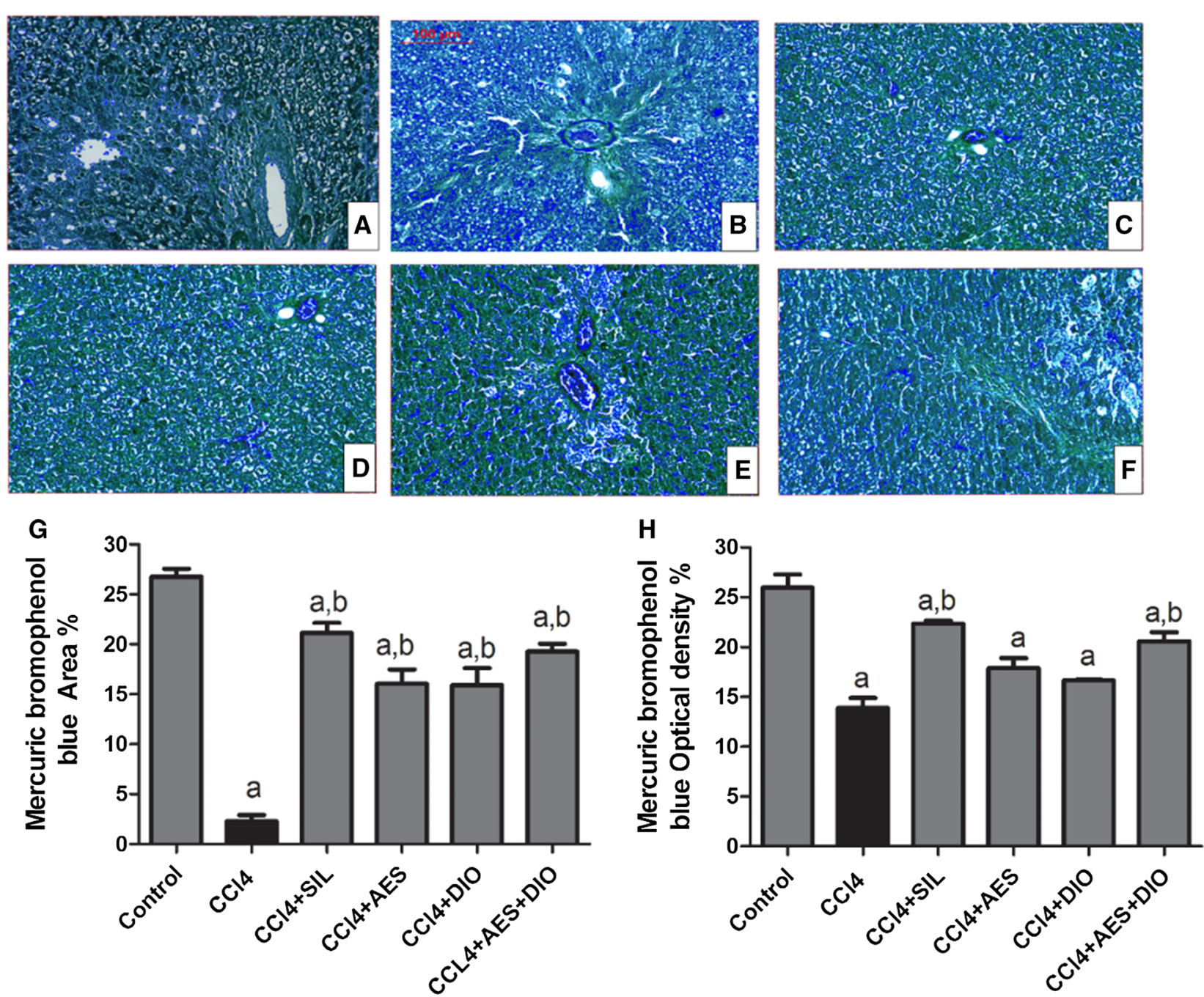

Fig. 3 Effects of AES and DIO each alone or in low-dose combination on the distribution of protein contents in liver tissue stained by Mercuric bromophenol blue reagent in the $\mathrm{CCl}_{4}$-induced liver rat model. A-F Representative images of mercuric bromophenol blue staining (blue area), $200 \times$ magnification, scale bar equals $500 \mu \mathrm{m}$. Mercuric bromophenol blue-positive area expression \% (G) and optical density \% (H) across 10 different fields for each rat section using Leica Qwin 500 Image Analyzer. Data are presented as mean $\pm S E M(n=6 / g r o u p)$. a $P<0.05$ vs. control group. b $\mathrm{P}<0.05$ vs. $\mathrm{CCl}_{4}$ group

$22.56 \pm 1.36$ respectively. Hepatotoxicity is always correlated with disruption in the synthesis and metabolism of glycogen and proteins. From the present findings, both protein and glycogen were reduced in $\mathrm{CCl}_{4}$ group. Poisonous effect on liver may mainly contribute to such reduction through the drug-induced necrosis of the plasma membrane, or via depleting energy sources needed for synthesizing protein and other metabolic events through obstructing the oxidative phosphorylation activity as documented elsewhere [32]. All tested preventive treatments successfully reversed such effect.

The control group showed the highest protein content (as reflected by Mercuric bromophenol blue positively stained area of the hepatocytes and its optical density of $26.75 \pm 0.812$ and $25.76 \pm 1.66$; Fig. 3). $\mathrm{CCl}_{4}$-intoxicated group showed the lowest comparable values of $2.29 \pm 0.61$ and $13.9 \pm 0.98$. Protected groups treated by AES and DIO showed varying degrees of protein content improvements; $16.037 \pm 1.45$ and $15.913 \pm 1.7$ and optical density of $17.88 \pm 1.01$ and $16.66 \pm 0.08$ respectively. The combined administration of AES and DIO at low dose, strengthened the stain reaction and showed marked improvement in the protein content of hepatocytes of $19.27 \pm 0.8$ and optical density of $20.59 \pm 0.9$. The present results of pre-administration of AES improved liver histology and function and significantly enhanced 
total hepatic glycogen and protein content. These results confirmed the hepatoprotective effect of AES as previously reported against liver damage induced by methyl parathion [15] and $\mathrm{CCl}_{4}[16,22]$ in rats. Although treatment with DIO do positively contribute to liver histology and function, the protective effect of DIO was less evident than that of AES. These hepatoprotective effects of DIO coincide with those of $[15,19,20]$. Interestingly, livers of rats in $\mathrm{CCl}_{4}$ group treated with both AES and DIO showed minimal inflammation, eosinophilic staining and degenerations with significant enhancements in overall glycogen and protein contents in liver.

\section{AES, DIO and their combination ameliorated oxidative stress and inflammation in $\mathrm{CCl}_{4}$-induced liver damage in rats}

The administration of SIL, AES, DIO and AES/DIO combination significantly attenuated the increment in serum MDA and nitric oxide (NO) levels and partly attenuated the decrement in glutathione (GSH), Catalase and protein kinase C (PKC). Compared to SIL, AES, DIO and AES/DIO groups, the treatment with combined AES and DIO showed the best effects against all examined oxidative stress markers (Additional file 2). Abundant evidence suggests that reactive oxygen species (ROS) and other free radicals are induced following hepatic insults with drugs like $\mathrm{CCl}_{4}$. The enzymatic/non-enzymatic defense system is the natural protec-tor against free radicals accumulation $[28,30]$. The accumulation of free radicals can cause decreased Catalase and GSH levels and a decline in capacity of scavenging free radicals. Consisting with previous report [30,33], liver damage shown in $\mathrm{CCl}_{4}$-treated group was associated with enhanced MDA and $\mathrm{NO}$ as well as depletion of GSH and Catalase. Oxidative stress is known to cause activation of several stress kinases such as PKC and leads to exacerbation of cell toxicity [34]. The elevation of PKC in the present work was in line with the results of the previous studies which suggested that the hepatic oxidative stress and injury induced by bezafibrate [34] and acetaminophen [35] and $\mathrm{CCl}_{4}$ [36] was mediated by elevation of PKC. PKC induces upregulation of tumor necrosis factor- $\alpha$ (TNF- $\alpha$ ), interleukin-6 (IL6), and ROS, a major contributor to $\mathrm{CCl}_{4}$-induced liver injury [36]. Here, and in agreement with results of [16], $\mathrm{AES}$ ameliorated $\mathrm{CCl}_{4}$-induced hepatotoxicity by reducing MDA and NO and increasing GSH activity. Similarly, in this study, DIO mitigated $\mathrm{CCl}_{4}$-induced oxidative and nitrative stresses confirming previous studies that showed that DIO alleviates the oxidative stress caused by aflatoxin [22], methotrexate [20] by increasing GSH levels, lowering NO levels, and enhancing the activity of antioxidant enzymes. Most interestingly, much improvement in oxidative stress and antioxidants status was observed here when AES was combined with DIO.

\section{Limitations}

This study was primarily focused on the assessment of tested extracts in induced liver fibrosis in animal model, more investigations are required for more understanding of the molecular mechanisms by which AES and DIO each alone or in low-dose combination might exert their beneficial hepatoprotective effect such as their effects on the inhibition of cytochrome CYP2E1 activity.

\section{Supplementary information}

Supplementary information accompanies this paper at https://doi. org/10.1186/s13104-020-05094-2.

Additional file 1. Detailed methods.

Additional file 2. Effects of AES and DIO each alone or in low-dose combination on oxidative stress and inflammatory markers in rats. Data are presented as mean \pm SEM $(n=6 /$ group). a $P<0.05$ vs. control group. b $P<0.05$ vs. $C C_{4}$ group, $c P<0.05$ vs SIL group, $d P<0.05$ vs AES group. e $\mathrm{P}<0.05$ vs DIO group, $\mathrm{f} P<0.05$ vs AES $+\mathrm{DIO}$.

\section{Abbreviations}

AES: Aescin; DIO: Diosmin; $\mathrm{CCl}_{4}$ : Carbon tetrachloride; SIL: Silymarin; PAS: Periodic acid Schiff; SPSS: Statistical package for social science; ALT: Alanine aminotransferase; AST: Aspartate aminotransferase; MDA: Malondialdehyde; NO: Nitric oxide; GSH: Glutathione; PKC: Protein kinase C; TNF-a: Tumor necrosis factor a; IL-6: Interleukin-6; ROS: Reactive oxygen species.

\section{Acknowledgements}

Authors thank Al-Jalila Foundation No. 215098 for partially funding this study for Amr Amin.

\section{Authors' contributions}

D, AS, NY, and SH conceived and designed research. SD, AS, NY, and SH conducted experiments. SD, AS, NY, and SH contributed materials, technical and analytical tools. SD, AS, NY, SH and $\mathrm{AH}$ analyzed data. $\mathrm{AH}, \mathrm{SH}$ and $\mathrm{AA}$ wrote the manuscript. All authors read and approved the manuscript.

\section{Funding}

Partially support by Al-Jalila Foundation No. 215098 was provided for Amr Amin

\section{Availability of data and materials}

All data supporting the conclusions of this article are included within the article and all datasets supporting our findings are available.

\section{Ethics approval and consent to participate}

All procedures in the animal studies complied with and are approved in accordance with the Ethics Committee of the National Research Centre and followed the recommendations of the National Institutes of Health Guide for Care and Use of Laboratory Animals.

\section{Consent to publish}

Not applicable.

\section{Competing interests}

The authors declare that they have no competing interests.

\section{Author details}

${ }^{1}$ Faculty of Pharmacy, Modern University for Technology and Information, Cairo, Egypt. ${ }^{2}$ Pharmacology Department, National Research Centre, Giza, Egypt. ${ }^{3}$ Biochemistry Department, Modern University for Technology and Information, Cairo, Egypt. ${ }^{4}$ Pathology Department, National Research Centre, Giza, Egypt. ${ }^{5}$ Hormone Evaluation Department, National Organization for Drug Control and Research, Giza, Egypt. ${ }^{6}$ Biology Department, UAE 
University, Al Ain, UAE. ${ }^{7}$ Present Address: The University of Chicago, Chicago, United States.

Received: 27 March 2020 Accepted: 16 May 2020

Published online: 27 May 2020

\section{References}

1. Wang FS, Fan JG, Zhang Z, Gao B, Wang HY. The global burden of liver disease: the major impact of China. Hepatology (Baltimore, MD). 2014;60(6):2099-108. https://doi.org/10.1002/hep.27406 (Epub 2014/08/29)

2. Ingawale DK, Mandlik SK, Naik SR. Models of hepatotoxicity and the underlying cellular, biochemical and immunological mechanism (s): a critical discussion. Environ Toxicol Pharmacol. 2014;37(1):118-33.

3. Boll M, LutzW, Becker E, Stampfl A. Mechanism of carbon tetrachloride-induced hepatotoxicity. Hepatocellular damage by reactive carbon tetrachloride metabolites. Zeitschrift für Naturforschung C. 2001;56(7-8):649-59.

4. Hamza AA, Heeba GH, Elwy HM, Murali C, El-Awady R, Amin A. Molecular characterization of the grape seeds extract's effect against chemically induced liver cancer: in vivo and in vitro analyses. Sci Rep. 2018;8:1-16.

5. El-Kharrag R, Amin A, Hisaindee S, Greish Y, Karam SM. Development of a therapeutic model of precancerous liver using crocin-coated magnetite nanoparticles. Int J Oncol. 2017;50:212-22.

6. Amin A, Hamza AA, Daoud S, Khazanehdari K, Al Hrout A, Baig B, Chaiboonchoe A, Adrian TE, Zaki N, Salehi-Ashtiani K. Saffron-based crocin prevents early lesions of liver cancer: in vivo, in vitro \& network analyses. Recent Patents Anti Cancer Drug Discov. 2016;11:121-33.

7. Amin A, Mahmoud-Ghoneim D. Texture analysis of liver fibrosis microscopic images: a study on the effect of biomarkers. Acta Biochim Biophys Sin. 2011;43(3):193-203.

8. Mahmoud-Ghoneim D, Amin A, Corr P. MRI-based texture analysis, a potential technique to assess protectors against induced-liver fibrosis in rats. Radiol Oncol. 2009;43(1):30-40.

9. Amin A. Chemopreventive effect of chlorella on the antioxidant system in DMBA-induced oxidative stress in liver. Int J Pharmacol. 2008;4(3):169-76.

10. Celep AGS, Yilmaz S, Coruh N. Antioxidant capacity and cytotoxicity of Aesculus hippocastanum on breast cancer MCF-7 cells. J Food Drug Anal. 2002;20:692-8.

11. Xiao G-m, Wei J. Effects of $\beta$-Aescin on the expression of nuclear factor-kB and tumor necrosis factor-a after traumatic brain injury in rats. J Zhejiang Univ Sci B. 2005;6(1):28.

12. Ji DB, Xu B, Liu JT, Ran FX, Cui JR. beta-Escin sodium inhibits inducible nitric oxide synthase expression via downregulation of the JAK/STAT pathway in A549 cells. Mol Carcinog. 2011;50(12):945-60. https://doi. org/10.1002/mc.20762 (Epub 2011/03/15)

13. Xin W, Zhang L, Sun F, Jiang N, Fan H, Wang T, et al. Escin exerts synergistic anti-inflammatory effects with low doses of glucocorticoids in vivo and in vitro. Phytomedicine. 2011;18(4):272-7.

14. Jiang $N$, Xin W, Wang T, Zhang L, Fan H, Du Y, et al. Protective effect of aescin from the seeds of Aesculus hippocastanum on liver injury induced by endotoxin in mice. Phytomedicine. 2011;18(14):1276-84. https://doi. org/10.1016/j.phymed.2011.06.011 (Epub 2011/08/02).

15. Du Y, Wang T, Jiang N, Ren R-T, Li C, Li C-K, et al. Sodium aescinate ameliorates liver injury induced by methyl parathion in rats. Exp Ther Med. 2012;3(5):818-22. https://doi.org/10.3892/etm.2012.479 (Epub 02/13).

16. Singh $\mathrm{H}$, Sidhu S, Chopra K, Khan M. The novel role of $\beta$-aescin in attenuating CCL4-induced hepatotoxicity in rats. Pharm Biol. 2017;55(1):749-57.

17. Szymański M, Młynarek D, Szymański A, Matławska I. Simultaneous determination of diosmin and hesperidin in pharmaceuticals by RPLC using ionic liquids as mobile phase modifiers. Iran J Pharm Res. 2016;15(1):141-8.

18. Katsenis K. Micronized purified flavonoid fraction (MPFF): a review of its pharmacological effects, therapeutic efficacy and benefits in the management of chronic venous insufficiency. Curr Vasc Pharmacol. 2005;3(1):1-9 (Epub 2005/01/12).

19. Tahir M, Rehman MU, Lateef A, Khan R, Khan AQ, Qamar W, et al. Diosmin protects against ethanol-induced hepatic injury via alleviation of inflammation and regulation of TNF-alpha and NF-kappaB activation. Alcohol. 2013;47(2):131-9. https://doi.org/10.1016/j.alcohol.2012.12.010 (Epub 2013/02/20).

20. Abdel-Daim MM, Khalifa HA, Abushouk Al, Dkhil MA, Al-Quraishy SA. Diosmin attenuates methotrexate-induced hepatic, renal, and cardiac injury: a biochemical and histopathological study in mice. Oxidative Med Cell Longevity. 2017;2017:10. https://doi.org/10.1155/2017/3281670.

21. Abdel-Reheim AM, Messiha BS, Abo-Saif A. Hepatoprotective effect of diosmin on iron-induced liver damage. Int J Pharmacol. 2017;13:529-40.

22. Eraslan G, Sarica ZS, Bayram LC, Tekeli MY, Kanbur M, Karabacak M. The effects of diosmin on aflatoxin-induced liver and kidney damage. Environ Sci Pollut Res Int. 2017;24(36):27931-41. https://doi.org/10.1007/s1135 6-017-0232-7 (Epub 2017/10/11).

23. Sharmila Queenthy S, Stanely Mainzen Prince P, John B. Diosmin prevents isoproterenol-induced heart mitochondrial oxidative stress in rats. Cardiovasc Toxicol. 2018;18(2):120-30. https://doi.org/10.1007/s1201 2-017-9422-2 (Epub 2017/08/19).

24. Li CC, Hsiang CY, Wu SL, Ho TY. Identification of novel mechanisms of silymarin on the carbon tetrachloride-induced liver fibrosis in mice by nuclear factor-kappaB bioluminescent imaging-guided transcriptomic analysis. Food Chem Toxicol. 2012;50(5):1568-75. https://doi. org/10.1016/j.fct.2012.02.025 (Epub 2012/03/06).

25. Germoush MO. Diosmin protects against cyclophosphamide-induced liver injury through attenuation of oxidative stress, inflammation and apoptosis. Int J Pharmacol. 2016;12:644-54.

26. Hotchkiss RD. A microchemical reaction resulting in the staining of polysaccharide structures in fixed tissue preparations. Arch Biochem. 1948;16(1):131-41 (Epub 1948/01/01).

27. Mazia D, Brewer PA, Alfert M. The Cytochemical staining and measurement of protein with mercuric bromphenol blue. Biol Bull. 1953;104(1):57-67. https://doi.org/10.2307/1538691.

28. Weber LW, Boll M, Stampfl A. Hepatotoxicity and mechanism of action of haloalkanes: carbon tetrachloride as a toxicological model. Crit Rev Toxicol. 2003;33(2):105-36. https://doi.org/10.1080/713611034 (Epub 2003/04/24)

29. Awaad AS, Soliman GA, El-Sayed DF, El-Gindi OD, Alqasoumi SI. Hepatoprotective activity of Cyperus alternifolius on carbon tetrachlorideinduced hepatotoxicity in rats. Pharm Biol. 2012;50(2):155-61. https://doi. org/10.3109/13880209.2011.580351 (Epub 2012/01/13).

30. Jayesh K, Helen LR, Vysakh A, Binil E, Latha. Protective role of Terminalia bellirica (Gaertn.) Roxb fruits against CCL4 induced oxidative stress and liver injury in rodent model. Indian J Clin Biochem. 2019;34(2):155-63.

31. Abdelhafez OH, Fawzy MA, Fahim JR, Desoukey SY, Krischke M, Mueller MJ, et al. Hepatoprotective potential of Malvaviscus arboreus against carbon tetrachloride-induced liver injury in rats. PLOS ONE. 2018;13(8):e0202362. https://doi.org/10.1371/journal.pone.0202362.

32. Abdel Salam OM, Baiuomy AR, El-Shenawy SM, Hassan NS. Effect of pentoxifylline on hepatic injury caused in the rat by the administration of carbon tetrachloride or acetaminophen. Pharmacol Rep. 2005;57(5):596-603.

33. Valko M, Leibfritz D, Moncol J, Cronin MT, Mazur M, Telser J. Free radicals and antioxidants in normal physiological functions and human disease. Int J Biochem Cell Biol. 2007;39(1):44-84. https://doi.org/10.1016/j.bioce 1.2006.07.001 (Epub 2006/09/19).

34. Nakajima T, Tanaka N, Li G, Hu R, Kamijo Y, Hara A, et al. Effect of bezafibrate on hepatic oxidative stress: comparison between conventional experimental doses and clinically-relevant doses in mice. Redox Rep. 2010;15(3):123-30.

35. Saberi B, Ybanez MD, Johnson HS, Gaarde WA, Han D, Kaplowitz N. Protein kinase $C$ (PKC) participates in acetaminophen hepatotoxicity through C-jun-N-terminal kinase (JNK)-dependent and-independent signaling pathways. Hepatology. 2014;59(4):1543-54.

36. Lee SJ, Kim SJ, Lee H-S, Kwon O-S. PKC $\delta$ mediates NF-KB inflammatory response and downregulates SIRT1 expression in liver fibrosis. Int J Mol Sci. 2019;20(18):4607.

\section{Publisher's Note}

Springer Nature remains neutral with regard to jurisdictional claims in published maps and institutional affiliations. 